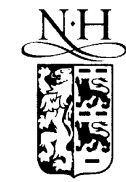

ELSEVIER

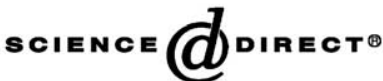

\title{
AFM search for slow MCI-produced nanodefects on atomically clean monocrystalline insulator surfaces
}

\author{
I.C. Gebeshuber *, S. Cernusca, F. Aumayr, HP. Winter \\ Institut für Allgemeine Physik, TU Wien, Wiedner Hauptstrasse 8-10, A-1040 Wien, Austria
}

\begin{abstract}
We have investigated by means of atomic force microscopy (AFM) single impacts of slow singly and multiply charged $\mathrm{Ar}$ ions on atomically clean insulator surfaces for $\mathrm{LiF}\left(\begin{array}{ll}1 & 0\end{array}\right), \mathrm{SiO}_{2}\left(\begin{array}{lll}0 & 0 & 1\end{array}\right) \alpha$-quartz, muscovite mica and sapphire $c$-plane $\mathrm{Al}_{2} \mathrm{O}_{3}\left(\begin{array}{lll}0 & 0 & 0\end{array}\right)$ crystals. The target samples have been continuously kept under UHV conditions by transferring them in a transportable UHV vault from the vacuum chamber for ion bombardment to the AFM instrument. Slow ion bombardment was accompanied by low-energy electron flooding to compensate for possible target surface charge-up. For $\mathrm{Al}_{2} \mathrm{O}_{3}$ clear ion-charge dependent surface defects in lateral and vertical directions give evidence for potential sputtering, which until now has only been demonstrated with thin polycrystalline insulator films.
\end{abstract}

(c) 2003 Elsevier Science B.V. All rights reserved.

PACS: 79.20.Rf; 68.37.Ps; 68.35.Dv

Keywords: Nanodefects; Insulators; HCI; In situ AFM; Monocrystalline insulator surfaces; Potential sputtering

\section{Introduction}

Impact of slow multicharged ions (MCI) $\mathrm{Z}^{q+}$ on certain insulator materials can give rise to considerably stronger ablation than the common kinetic sputtering by neutral or singly charged projectiles. First experimental evidence for such "potential sputtering" (PS) was reported by Radzhabov et al. [1] and Morozov et al. [2], who for some alkalihalide surfaces observed strongly $q$ dependent secondary ion yields. Their results have been explained by "Coulomb explosion" [3], i.e. the creation of small positively charged surface

\footnotetext{
${ }^{*}$ Corresponding author. Tel.: +43-1-58801-13484; fax: +431-58801-13499.

E-mail address: ille@iap.tuwien.ac.at (I.C. Gebeshuber).
}

spots from rapid electron capture by the impinging MCI, with subsequent ablation because of the strong mutual target ion repulsion. As further evidence for PS, much larger etching patterns have been found on $\mathrm{KCl}$ crystal surfaces irradiated with $500 \mathrm{eV} \mathrm{Kr}^{4+}$ than with equally fast $\mathrm{Kr}^{+}$ions [4]. "Coulomb explosion" was also invoked for explaining atomic force microscopy (AFM) observations of blister-like defects on mica samples which had been bombarded with highly charged ions as $\mathrm{Xe}^{44+}$ and $\mathrm{U}^{70+}$ of several $100 \mathrm{keV}$ impact energy [5]. On the other hand, studies involving the impact of slow $(\leqslant 1 \mathrm{keV})$ MCI on thin polycrystalline films of alkalihalides $(\mathrm{LiF}, \mathrm{NaCl})$ and $\mathrm{Al}_{2} \mathrm{O}_{3}$ deposited on microbalance quartz crystals [6] did suggest another explanation for PS, namely defectstimulated desorption induced by the rapid electron capture [7]. Such desorption processes have 
earlier been studied for impact of electrons (ESD) or photons (PSD) on materials in which a selftrapping of specific crystal defects can take place [8], which proceeds by electron-phonon coupling. However, for impact of faster ions the defect trapping necessary for PS can also be forced or at least supported by kinetic projectile energy ("kinetically assisted PS" [9]), which fact may explain PS-like effects reported for target species where no electron-phonon coupling can take place [5].

We have carried out a systematic search for PS with atomically clean monocrystalline insulator targets which have been bombarded by low-energetic ions on the single impact level, by searching for resulting surface defects by means of AFM. The targets remained under UHV conditions during ion irradiation and subsequent AFM inspection. An important motivation for this study are interesting applications of PS for, e.g., nanostructuring of insulator surfaces. There are also suspicions that earlier PS studies involving polycrystalline insulator films might have been influenced by some defects in these target samples.

\section{Experimental methods}

We have looked for nanodefects on freshly

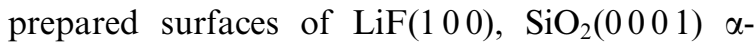
quartz, muscovite mica and sapphire $c$-plane $\mathrm{Al}_{2} \mathrm{O}_{3}\left(\begin{array}{lll}0 & 0 & 0\end{array}\right)$ after their irradiation with low doses of slow singly and multiply charged ions. The ion bombardment was accompanied by low-energy electron flooding to compensate for surface charge-up which otherwise would have strongly inhibited the AFM observation. The applied electron gun produced very slow electrons $(4 \mathrm{eV}$ energy, $200 \mathrm{nA}$ current, $2 \mathrm{~cm}$ distance to the sample).

In a first stage of this study we had used a NIER-type electron impact ion source with its turbomolecular pump directly attached to our UHV-AFM instrument [10]. However, in this arrangement inconveniently high AFM system noise was produced. We then changed to a transportable UHV vault for target transfer which is alternatingly coupled by UHV locks to the target irradiation chamber and the AFM. This procedure kept target surfaces under permanent UHV conditions after their initial cleaning, thermal annealing and subsequent irradiation until completion of their AFM inspection, and also drastically reduced the disturbing AFM system noise. Singly and multiply charged ions for target irradiation have been extracted from a $5 \mathrm{GHz}$ ECR ion source [11], magnetically analyzed and guided via electrostatic lenses to the UHV irradiation chamber. The ions were decelerated in front of the target surface to their desired impact energy.

\section{Description of the AFM observations}

In the following we describe so far gained experience from AFM observations of different insulator target surfaces. In all measurements the AFM contact mode has been employed, and sometimes also other AFM modes (non-contact, lateral force) have been used. Where possible, our results are compared with similar work from other groups.

\section{1. $\operatorname{LiF}(100)$}

Nanoscale modifications of different alkalihalide surfaces $(\mathrm{NaCl}, \mathrm{KCl}, \mathrm{KBr})$ induced by electronic transitions (ESD, PSD) have been studied with AFM down to atomic resolution [12]. In our

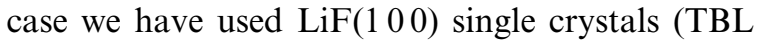
Kelpin, Neuhausen, Germany) which were cleaved in air, $\mathrm{CO}_{2}$ snow cleaned (Applied Surface Technologies, New Providence, NJ, USA), transferred into the UHV irradiation chamber and annealed at $400{ }^{\circ} \mathrm{C}$ for $3 \mathrm{~h} . \mathrm{CO}_{2}$ snow cleaning is an efficient way to remove micro- and nanometer sized debris from single-crystal surfaces. With this crystal preparation techniques we could routinely image monoatomic terraces with atomic resolution in the AFM contact mode. However, the complex structure of the $\operatorname{LiF}(100)$ surface resulting after slow ion bombardment made a correlation of possible ion induced nanodefects to ion doses and charge states rather difficult. So far, we could not find significant changes in surface topography between the unbombarded $\operatorname{LiF}(100)$ surfaces and their bombardment with $100 \mathrm{eV} \mathrm{Ar}^{2+}, 400 \mathrm{eV}$ $\mathrm{Ar}^{2+}, 250 \mathrm{eV} \mathrm{Ar}^{3+}$ and even $3 \mathrm{keV} \mathrm{Ar}^{7+}$. For 


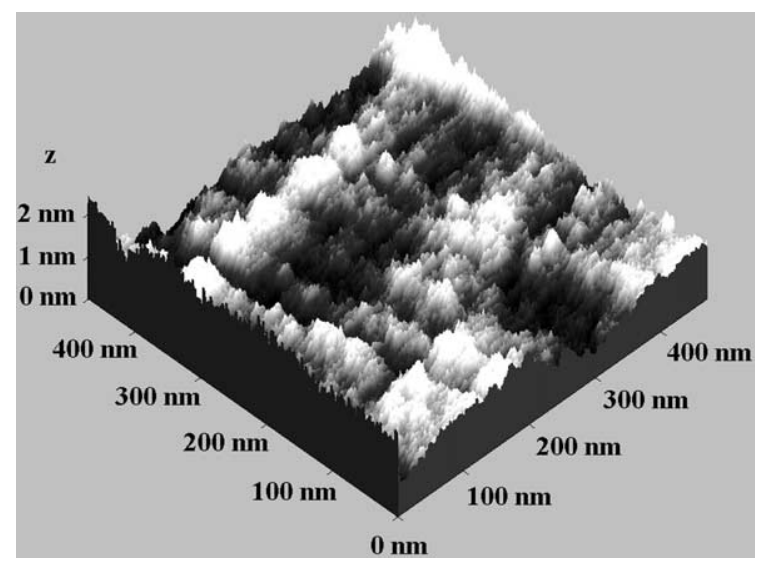

Fig. 1. $\operatorname{LiF}\left(\begin{array}{lll}1 & 0 & 0\end{array}\right)$ single-crystal surfaces after standard preparation (see text) and bombardment with $250 \mathrm{eV} \mathrm{Ar}^{3+}$ ions $\left(480 \times 480 \mathrm{~nm}^{2}\right.$, imaging parameter height $\left.z\right)$.

demonstration, Fig. 1 shows a $\operatorname{LiF}\left(\begin{array}{lll}1 & 0 & 0\end{array}\right)$ surface after preparation and bombardment with $\mathrm{Ar}^{3+}$ ions with a dose of $5 \times 10^{12}$ ions $/ \mathrm{cm}^{2}$ (i.e. about five ions per $10 \times 10 \mathrm{~nm}^{2}$ only). Bombardment with $100 \mathrm{eV} \mathrm{Ar}^{2+}$ ions with larger doses up to $5 \times 10^{15}$ ions $/ \mathrm{cm}^{2}$ did not produce distinctive changes in surface topography. The investigations

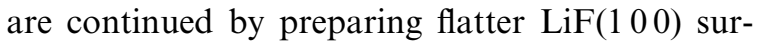
faces on which the ion induced defects can probably be diagnosed, which will be important for comparison with our earlier studies on PS involving polycrystalline LiF films [7].

\section{2. $\mathrm{SiO}_{2}(0001)$}

Quartz is the only monocrystalline target surface for which the microbalance technique has been applied in order to demonstrate PS [13]. For the present work, polished $\mathrm{SiO}_{2}\left(\begin{array}{lll}0 & 0 & 0\end{array}\right) \alpha$-quartz single crystals (TBL Kelpin, Neuhausen, Germany) were $\mathrm{CO}_{2}$ snow cleaned and annealed in UHV at $400{ }^{\circ} \mathrm{C}$ for $3 \mathrm{~h}$. This procedure resulted in very flat crystal surfaces for which our AFM contact mode measurements on fourteen samples revealed a root-mean-squares (rms) roughness of $0.16 \pm 0.01 \mathrm{~nm}$, as a hopefully excellent start for our PS investigations. These quartz crystals were then bombarded with $1 \mathrm{keV} \mathrm{Ar}^{+}$ions. AFM imaging of resulting surface topography indeed clearly revealed ion induced nanostructures as

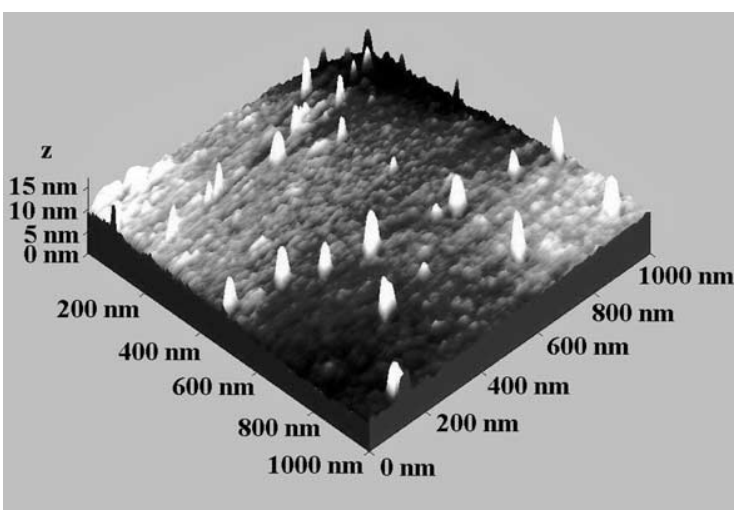

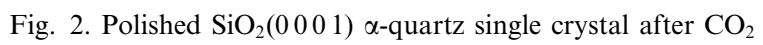
cleaning, annealing and bombardment with $1 \mathrm{keV} \mathrm{Ar}^{+}$ions (UHV AFM contact mode). Ion bombardment results in hillocks with a height of several nanometers.

shown in Fig. 2. The surface is covered with hillocks a few nanometers high. However, the density of these hillocks did not directly correspond to the applied ion doses: for a dosis of about one incident $1 \mathrm{keV} \mathrm{Ar}{ }^{+}$ion per $10 \times 10 \mathrm{~nm}^{2}$, we observe only about 30 nanostructures on an area of $1000 \times 1000$ $\mathrm{nm}^{2}$, which indicates that not every single ion has caused one nanodefect on the quartz surface. Probably several ion impacts are necessary to induce a detectable surface modification: the ion dosis in all cases reported in this paper was $5 \times 10^{12}$ ions $/ \mathrm{cm}^{2}$, equivalent to five incident ions per $10 \times 10 \mathrm{~nm}^{2}$. Probably individual ion tracks do not need to overlap to induce multiple ion induced nanostructures, but may cause defects on the insulator surface which increase the chance that impact of another ion in the near vicinity gives rise to an observable surface structure. The fact that surface modifications found after ion bombardment are observed as hillocks instead of craters is also not yet understood, but several possible explanations can be conceivable: in AFM as for other scanning probe microscopy methods it is more straightforward to image elevated structures than craters. Even worse, narrow but highly elevated surface features in the vicinity of craters would completely mask the latter because of their convolution with the tip shape.

So far, very few studies have been performed in this field, in particular for insulating surfaces. 
Several groups having applied AFM did report hillocks as surface modifications after bombardment with heavy ions, in some cases even for $\mathrm{GeV}$ impact energies. Audouard et al. [14] studied by AFM the surface of amorphous metals irradiated with swift heavy ions. The ion impacts apparently caused formation of hillocks for irradiation at 300 $\mathrm{K}$ if the ions provided sufficiently large electronic stopping ( $>55 \mathrm{keV} / \mathrm{nm})$. On the other hand, irradiation at $80 \mathrm{~K}$ did not induce noticeable modifications of the metal surface. These results indicate that formation of hillocks which are flattened by the sample growth, is essentially caused by the damage from electronic excitation in individual ion tracks. In another experiment the same group [15] studied with AFM modifications of the surface topography of amorphous metallic alloys. Irradiation with swift $\mathrm{Pb}$ or $\mathrm{U}$ ions led to formation of hillocks surrounded by craters, whereas no visible surface modifications were observed after irradiation with $\mathrm{Kr}$ ions which caused less electronic stopping. In the view of these authors formation of hillocks can be ascribed to damage created in individual ion tracks, while craters would be linked to the occurrence of anisotropic growth. Both processes are induced by severe electronic excitation in the wake of incident ions.

\section{3. $\mathrm{KAl}_{2}\left[\mathrm{AlSi}_{3}\right] \mathrm{O}_{10}(\mathrm{OH})_{2}$ (muscovite mica)}

Muscovite mica is an aluminosilicate growing in sheets. Our mica samples which have been provided by Omicron Nanotechnology can be easily prepared to atomical flatness by cleavage in air with adhesive tape. The samples were then transferred to UHV and annealed for $3 \mathrm{~h}$ at $400{ }^{\circ} \mathrm{C}$. We could routinely obtain atomic resolution on these mica surfaces both in the AFM height mode and the lateral force mode. Mica features large atomically flat terraces with small steps between them. In searching for nanodefect formation by singly and multiply charged ions we bombarded these mica surfaces with $400 \mathrm{eV} \mathrm{Ar}{ }^{+}, 500 \mathrm{eV} \mathrm{Ar}{ }^{+}, \mathrm{Ar}^{2+}$ and $\mathrm{Ar}^{7+}, 800 \mathrm{eV} \mathrm{Ar}^{+}$and $\mathrm{Ar}^{4+}, 1 \mathrm{keV} \mathrm{Ar}^{+}$and $1.2 \mathrm{keV} \mathrm{Ar}^{+}$. After bombardment with the slowest ions $\left(400 \mathrm{eV} \mathrm{Ar}^{+}, 500 \mathrm{eV} \mathrm{Ar}^{+}\right.$and $\mathrm{Ar}^{2+}$ ) no surface modifications were found in AFM contact as well as non-contact modes. For bombardment by 800
$\mathrm{eV} \mathrm{Ar}^{+}$and $\mathrm{Ar}^{4+}$ only very few nanodefects could be seen on the irradiated surfaces. We observed hillocks with a few nanometers high and about $50 \mathrm{~nm}$ in diameter. They appeared in very low densities on the surface and might not necessarily have been caused by the ion bombardment. Surface modifications could only be attributed unambiguously to ion bombardment for $\geqslant 1 \mathrm{keV}$ $\mathrm{Ar}^{+}$ions. Fig. 3 shows a mica surface after $1.2 \mathrm{keV}$ $\mathrm{Ar}^{+}$ion bombardment where the density of observable surface nanodefects was already considerably larger than for $1 \mathrm{keV} \mathrm{Ar}^{+}$impacts administered with similar doses $\left(1 \mathrm{keV} \mathrm{Ar}^{+}\right.$ions induced about 10 nanodefects per $1000 \times 1000$ $\mathrm{nm}^{2}$, whereas for $1.2 \mathrm{keV} \mathrm{Ar}^{+}$ions the density of ion induced nanodefects was about 200 per $1000 \times 1000 \mathrm{~nm}^{2}$ ). However, also for mica no clear dependence on the ion-charge state could be found, so far. Several groups have performed AFM investigations of mica surfaces irradiated with highly charged ions. All these investigations were made on ambient air conditions.

We believe that only under UHV conditions imposed throughout the procedures of irradiation and AFM for investigating ion induced nanodefects an indisputable assignment of the latter to MCI bombardment is possible. Anyhow, as a general result from these studies MCI impact on mica left bumps with about $1 \mathrm{~nm}$ height and $15 \mathrm{~nm}$

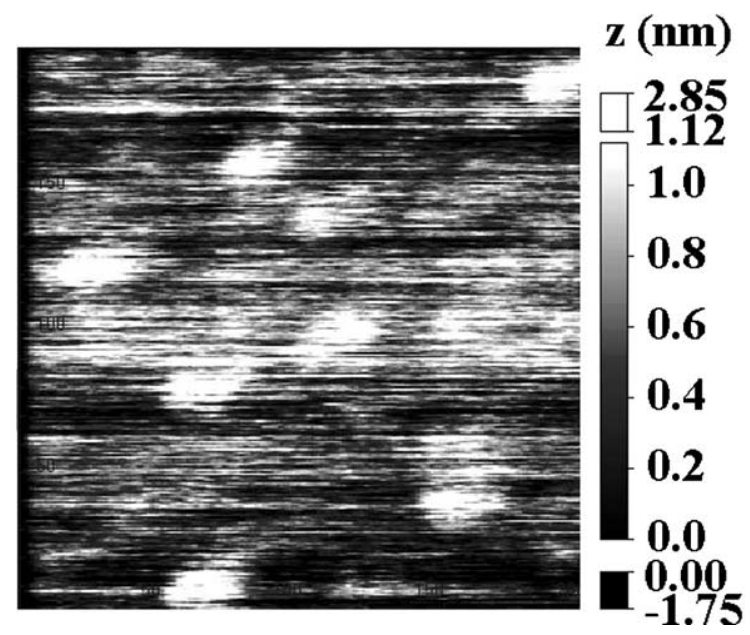

Fig. 3. AFM scan of muscovite mica bombarded with $1.2 \mathrm{keV}$ $\mathrm{Ar}^{+}$ions. Observed features are ion induced topographic defects. 
diameter. Parks et al. [16] showed that the size of these bumps was not strongly correlated to the kinetic ion energy. This work was later extended in order to demonstrate that the size of observed nanodefects was strongly correlated with the potential ion energy [17]. With $100 \mathrm{keV} \mathrm{Xe}^{q+}$ ions $(25 \leqslant q \leqslant 50)$ impinging on mica, damage caused by single ion impacts was observed with AFM at ambient conditions, with the impact sites typically appearing as circular hillocks. In the view of these authors this hillock- rather than crater-like feature
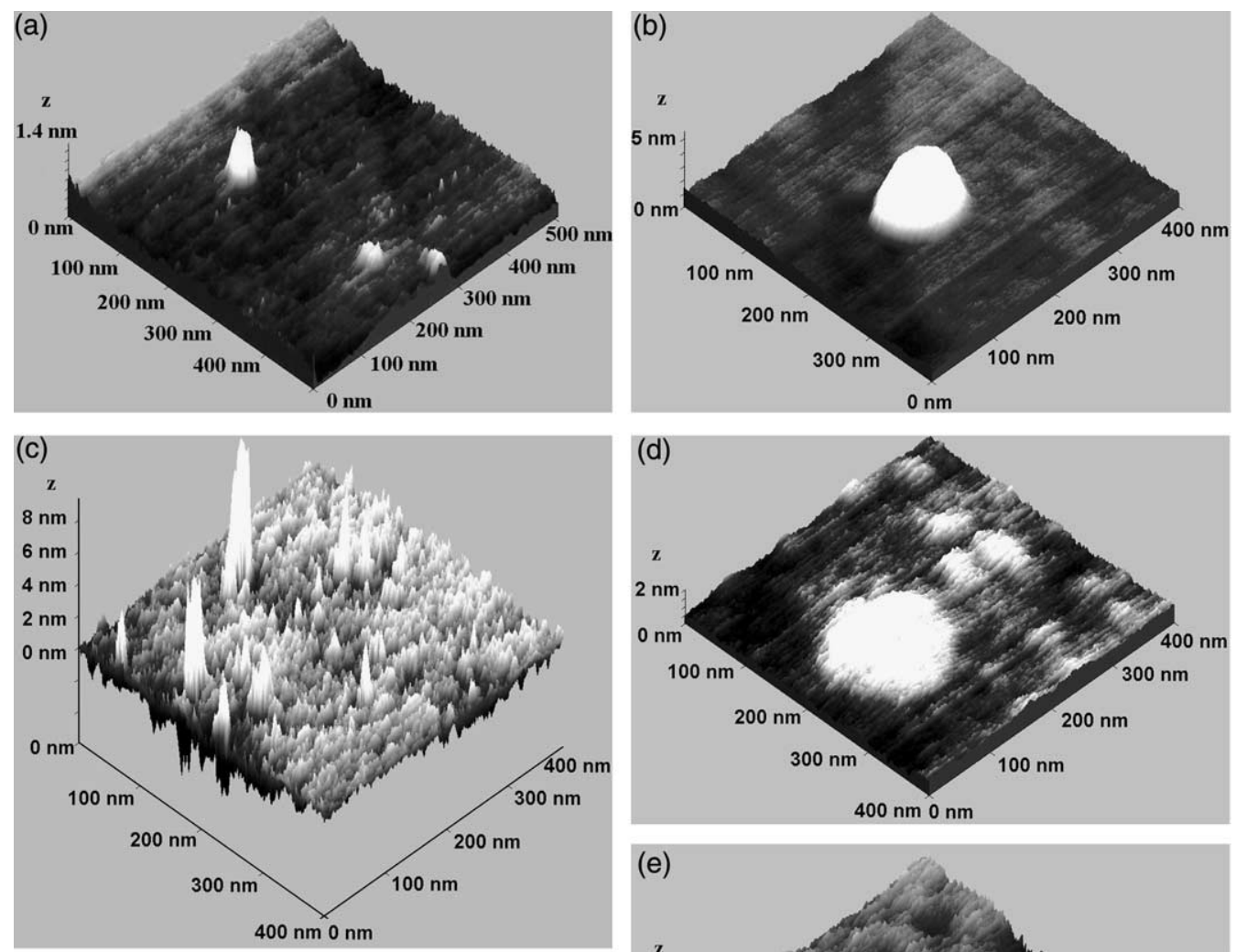

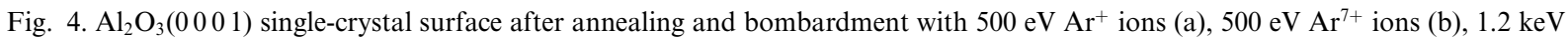
$\mathrm{Ar}^{1+}$ ions (c), $1.2 \mathrm{keV} \mathrm{Ar}^{4+}$ ions (d) and $1.2 \mathrm{keV} \mathrm{Ar}^{7+}$ ions (e).
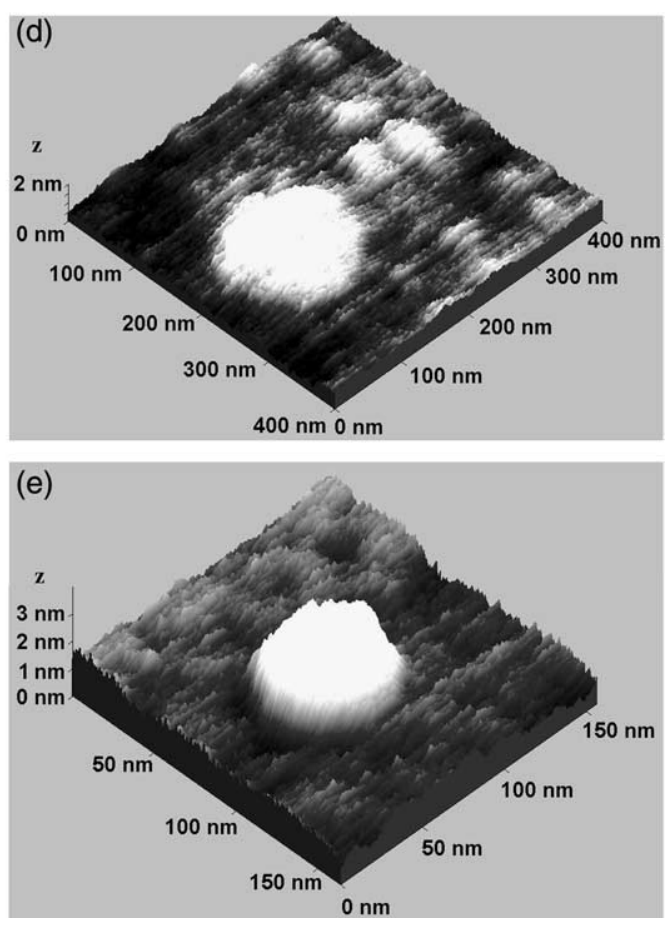

is caused by the highly anisotropically layered structure of mica.

\section{4. $\mathrm{Al}_{2} \mathrm{O}_{3}(0001)$}

Polished $\mathrm{Al}_{2} \mathrm{O}_{3}\left(\begin{array}{llll}0 & 0 & 0 & 1\end{array}\right)$-plane single crystals (TBL Kelpin, Neuhausen, Germany) have been $\mathrm{CO}_{2}$ snow cleaned and annealed for $3 \mathrm{~h}$ at $400{ }^{\circ} \mathrm{C}$ in UHV. This yielded as for $\mathrm{SiO}_{2}$ very flat crystal surfaces. AFM contact mode studies on numerous samples prepared by this technique revealed a rms 
roughness of $0.09 \pm 0.06 \mathrm{~nm}$. Bombardment with Ar ions with different charge states and kinetic energies $\left(500 \mathrm{eV} \mathrm{Ar}{ }^{+}, \mathrm{Ar}^{7+}, 1.2 \mathrm{keV} \mathrm{Ar}{ }^{+}, \mathrm{Ar}^{4+}\right.$ and $\mathrm{Ar}^{7+}$ ) resulted in hillock-like nanodefects seen in AFM contact mode (cf. Fig. 4(a)-(e)). The density of ion induced nanodefects did not directly correspond to the applied ion dose but was rather small, however reproducible: about 10 nanodefects per $1000 \times 1000 \mathrm{~nm}^{2}$ can be observed after bombardement in the energy range reported in this paper. Such a direct correspondence has only been found in STM investigations of HOPG [18]. However, on the $\mathrm{Al}_{2} \mathrm{O}_{3} c$-plane crystals we could show a clear correlation of slow ion induced defects with both kinetic energy and charge state of the projectile ions. We also found that the defects caused by slow ion impact could completely be removed by annealing the $\mathrm{Al}_{2} \mathrm{O}_{3}$ crystals at $450{ }^{\circ} \mathrm{C}$ for about 5 h. $500 \mathrm{eV} \mathrm{Ar}^{+}$ion impact produced defects with about one nanometer heigth and some tens of nanometers width (Fig. 4(a)). One should keep in mind that with AFM the height of surface features can more accurately be measured than their lateral dimension. Defects produced by $500 \mathrm{eV} \mathrm{Ar}^{7+}$ ions were several nanometers high (see Fig. 4(b)) and had lateral dimensions of about 100 (!) nanometers. At higher kinetic ion energy differences of ion induced nanodefects became even more distinct. $1.2 \mathrm{keV} \mathrm{Ar}^{+}$induced defects were up to $8 \mathrm{~nm}$ high and some ten nanometers wide (Fig. 4(c)). For impact of higher charged $\mathrm{Ar}^{4+}$ two different kinds of defects appeared on the surface (Fig. 4(d)) with similar heights of about $2 \mathrm{~nm}$, but considerably different lateral extensions.

Some were nearly $200 \mathrm{~nm}$ wide, but smaller defects (only about $50 \mathrm{~nm}$ wide) were found as well. Finally, for impact of $\mathrm{Ar}^{7+}$ only one kind of defects was visible in the AFM images, measuring about $50 \mathrm{~nm}$ across and $2 \mathrm{~nm}$ in height (see Fig. 4(e)).

\section{Summary and conclusions}

The present study describes systematic efforts to find evidence for PS by means of AFM inspection of atomically clean monocrystalline insulator surfaces which have been bombarded by slow (typically $\leqslant 1 \mathrm{keV}$ ) singly and multiply charged $\mathrm{Ar}^{q+}$ ions (up to $q=7$ ). The study may be seen as an extension of earlier work by other groups who looked for similar effects. In contrast to the present work, however, they have shot much faster multiply charged ions on various gas-covered surfaces and inspected them by AFM in air $[5,16,17]$, or made STM investigations of atomically clean HOPG surfaces bombarded by slow $(150 \mathrm{eV}) \mathrm{Ar}^{q+}$ ions (up to $q=9$ [18]) or much faster (several 100 $\mathrm{keV}$ ) $\mathrm{Xe}^{q+}$ ions (up to $q=44$ [19]). AFM in UHV is probably indispensable for finding clear-cut evidence of PS related nanodefects induced by slow MCI with a size clearly depending on the ioncharge state. In this work $\mathrm{Al}_{2} \mathrm{O}_{3}$ has been identified as a good candidate for such PS induced nanostructuring, and for $\mathrm{SiO}_{2}$ further research might lead to a similar conclusion. Both materials are of great relevance for applications in a rapidly emerging field combining microelectronics and nanotechnology.

Our studies on atomically clean insulator surfaces indicate that the PS effect - which has been found to be rather strong for thin films of the materials investigated here - might be more dependent on defect-mediation than so far assumed. For sure, we see potential energy dependent nanodefects generated on the single-crystal surfaces, but their density is too low to prove that the PS effects in thin films and single crystals are of equal importance.

Our expectations concerning the use of PS on monocrystalline surfaces for, e.g., nanostructuring applications, which originated from our previous experience with thin films, have not been met so far. Further studies along these lines are thus highly desirable.

\section{Acknowledgements}

This work has been supported by Austrian FWF under project no. 13543-PHY. The authors thank Dr. R. Wörgötter-Plunger for her cooperation in the early phase of these investigations.

\section{References}

[1] S.S. Radzhabov, R.R. Rakhimov, P. Abdusalamov, Izv. Akad. Nauk SSSR Ser. Fiz. 40 (1976) 2543. 
[2] S.N. Morozov, D.D. Gurich, T.U. Arifov, Izv. Akad. Nauk SSSR Ser. Fiz. 43 (1979) 137.

[3] I.S. Bitensky, M.N. Murakhmetov, E.S. Parilis, Sov. Phys. Tech. Phys. 24 (1979) 618.

[4] S.S. Radzhabov, R.R. Rakhimov, Izv. Akad. Nauk SSSR Ser. Fiz. 49 (1985) 1812.

[5] D.H. Schneider, M.A. Briere, J. McDonald, J. Biersack, Radiat. Eff. Def. Solids 127 (1993) 113.

[6] G. Hayderer, M. Schmid, P. Varga, HP. Winter, F. Aumayr, Rev. Sci. Instr. 70 (1999) 3696.

[7] F. Aumayr, J. Burgdörfer, P. Varga, HP. Winter, Comments At. Mol. Phys. 34 (1999) 201.

[8] P. Townsend, in: R. Behrisch (Ed.), Sputtering by Particle Bombardment II, Springer, Berlin, 1983, p. 147 (Chapter 4).

[9] G. Hayderer, S. Cernusca, M. Schmid, P. Varga, HP. Winter, F. Aumayr, D. Niemann, V. Hoffmann, N. Stolterfoht, C. Lemell, et al., Phys. Rev. Lett. 86 (2001) 3530.

[10] UHV-AFM/STM, OMICRON Nanotechnology GmbH, Germany.
[11] M. Leitner, D. Wutte, J. Brandstötter, F. Aumayr, HP. Winter, Rev. Sci. Instr. 65 (1994) 1091.

[12] M. Szymonski, J. Kolodziej, B. Such, P. Piatkowski, P. Struski, P. Czuba, F. Krok, Prog. Surf. Sci. 67 (2001) 123.

[13] M. Sporn, G. Libiseller, T. Neidhart, M. Schmid, F. Aumayr, HP. Winter, P. Varga, M. Grether, D. Niemann, N. Stolterfoht, Phys. Rev. Lett. 79 (1997) 945.

[14] A. Audouard, R. Mamy, M. Toulemonde, G. Szenes, L. Thomé, Nucl. Instr. and Meth. B 146 (1998) 217.

[15] A. Audouard, R. Mamy, M. Toulemonde, G. Szenes, L. Thomé, Europhys. Lett. 40 (1997) 527.

[16] D.C. Parks, R. Bastasz, R.W. Schmieder, M. Stoeckli, J. Vac. Sci. Technol. B 13 (1995) 941.

[17] D.C. Parks, F.G. Serpa, J.D. Gillaspy, M.P. Stoeckli, L.P. Ratliff, E.W. Bell, R.W. Schmieder, Nucl. Instr. and Meth. B 134 (1998) 46.

[18] G. Hayderer, S. Cernusca, M. Schmid, P. Varga, HP. Winter, F. Aumayr, Phys. Scr. T 92 (2001) 156.

[19] R. Minniti, L.P. Ratliff, J.D. Gillaspy, Phys. Scr. T 92 (2001) 22. 